\title{
Diagnostic Value of Neutrophil to Lymphocyte Ratio in Non-Alcoholic Fatty Liver Disease Evaluated Using Transient Elastography (TE) with Controlled Attenuated Parameter (CAP)
}

\author{
Cosmas Rinaldi Adithya \\ Lesmana (iD) 1,2 \\ Yoppi Kencana' \\ Ikhwan Rinaldi iD ${ }^{3}$ \\ Juferdy Kurniawan' \\ Irsan Hasan ' \\ Andri Sanityoso Sulaiman' \\ Rino Alvani Gani ${ }^{\prime}$ \\ 'Department of Internal Medicine, \\ Hepatobiliary Division, Dr. Cipto \\ Mangunkusumo National General \\ Hospital, Universitas Indonesia, Jakarta, \\ Indonesia; ${ }^{2}$ Digestive Disease \& GI \\ Oncology Center, Medistra Hospital, \\ Jakarta, Indonesia; ${ }^{3}$ Department of \\ Internal Medicine, Haematology and \\ Oncology Division, Dr. Cipto \\ Mangunkusumo National General \\ Hospital, Universitas Indonesia, Jakarta, \\ Indonesia
}

Background: Non-alcoholic fatty liver disease (NAFLD) is a chronic inflammatory disease with excessive fat accumulation in the liver. Transient elastography (TE) with controlled attenuation parameter (CAP) is a device and method to examine the degree of fibrosis and steatosis. However, this device is not widely available across Indonesia. Neutrophil and lymphocyte ratio (NLR) is a simple marker for inflammation, which has a potency to predict disease outcome. This study aims to know the diagnostic value of NLR as the indicator of steatosis and fibrosis severity.

Methods: This was a cross-sectional study with consecutive sample collection. We used secondary data from medical records, starting from 2016 to 2018. A descriptive and data analysis, including correlation test, multivariate linear regression, $t$-test, receiver operating curve (ROC) and area under the curve (AUC) were done to find out the outcome of the study. Statistical analyses were performed using Statistical Package for Social Sciences (SPSS) Version 20.0 (SPSS Inc, Chicago, Illinois). A P value $<0.05$ was considered as statistically significant.

Results: Out of 106 subjects, $62.3 \%$ patients were women with the mean of age 57.29 years old and $77.4 \%$ had metabolic syndrome. Most patients had moderate to severe steatosis degree $(66 \%)$ with the mean of TE mean $6.14(2.8-18.2) \mathrm{kPa}$. There was a positive correlation between CAP and TE compared with NLR with $r=0.648(\mathrm{p}<0.001)$ and $\mathrm{r}=0.621$ $(p<0.001)$, respectively. The use of RNL to assess moderate-severe steatosis has a cutoff point of 1.775 with sensitivity, specificity, PPV and NPV, respectively, at $81.5 \%, 80.6 \%$, $89.1 \%$, and $69.1 \%$; cutoff point 2.150 to assess significant fibrosis with sensitivity, specificity, PPV and NPV of $92.3 \%, 87.5 \%, 70.6 \%$, and $97.2 \%$, respectively.

Conclusion: NLR has a positive and significant correlation with the degree of steatosis and fibrosis with high sensitivity and specificity as evaluated by TE/CAP.

Keywords: neutrophil and lymphocyte ratio, steatosis, fibrosis, non-alcoholic fatty liver disease

\section{Introduction}

Non-alcoholic fatty liver disease (NAFLD) is a chronic liver disease characterized by excessive accumulation of fat in the liver. ${ }^{1,2}$ Its prevalence is increasing worldwide by around $20 \%$, with $3-5 \%$ progress to NASH (Non-alcoholic Steatohepatitis). ${ }^{1}$ In Asia, the prevalence of NAFLD was reported at $13 \%$ in 1990 , which later became $30 \%$ in

\footnotetext{
Correspondence: Cosmas Rinaldi Adithya Lesmana

Department of Internal Medicine, Hepatobiliary Division, Dr. Cipto Mangunkusumo National General Hospital, Universitas Indonesia, Jalan Diponegoro No. 7I, Jakarta, Indonesia Email medicaldr200Iid@yahoo.com
} 
2008. ${ }^{3}$ NAFLD prevalence in Indonesia, which represents the biggest Southeast Asian country, was reported to be $30 \%$ in 2002 and later it increased until 51\% in $2015 .{ }^{4,5}$ NAFLD presentations have a broad spectrum, ranging from simple steatosis (NAFL) to advance liver disease, where $5-8 \%$ will then become liver cirrhosis in 5 years, then $12.8 \%$ of cirrhosis patients will further develop hepatocellular carcinoma (HCC) within 3 years. ${ }^{6}$ Currently, NAFLD is considered to be the third most frequent cause of HCC in the United States, and liver transplantation due to cirrhosis associated with NASH is the second most common cause of transplantation in the United States, and is expected to be the most common cause of transplantation in the future. ${ }^{2}$

The old paradigm considers NAFL to be a benign condition, the tendency to develop into cirrhosis and HCC development was considered very low. ${ }^{2}$ Nevertheless, we cannot underestimate NAFL. ${ }^{7,8}$ In general, this disease is closely related to the metabolic syndrome and its components. ${ }^{9-11}$ At least one component of metabolic syndrome is owned by $90 \%$ of individuals with NAFLD, and $33 \%$ of NAFLD have all components of the metabolic syndrome. ${ }^{11}$

Liver biopsy is still considered the gold standard for diagnosing NASH, but this procedure is less preferred because of its possible complications, such as bleeding and even death (1: 10.000). ${ }^{12,13}$ In addition, this procedure is also costly, has a large sampling error ( $\pm 1 / 50.000$ total volume), poor reproducibility, and is strongly influenced by the operator who does it as well as the pathologist who assesses the liver specimen. ${ }^{12,14}$ Transient elastography (TE) is a noninvasive and rapid measurement tool, which has been proven to have a good accuracy in evaluating the degree of liver fibrosis and steatosis. ${ }^{14,15}$ The advantages of this tool are easy, fast, can be repeated to assess the progression of the disease, not affected by the operator, and can assess the liver part 100 times greater than liver biopsy. ${ }^{14}$ However, this modality might not be available in all hospitals, especially in the remote area.

Chronic inflammation plays an important role in the development of NAFLD. ${ }^{16}$ A large amount of evidence suggests that proinflammatory mediators secreted by visceral adipose tissue, intestinal endotoxin, endoplasmic reticulum, and innate immunity all play key roles. ${ }^{17,18}$ The Neutrophil to Lymphocyte Ratio (NLR) is a simple inflammatory marker that has been used to predict outcomes in patients with cancer and coronary artery disease and has also been shown to be correlated with the main histological features of NAFLD, including inflammation and fibrosis. ${ }^{19-21}$
Studies of NLR with NASH and the degree of fibrosis examined by a liver biopsy have been widely carried out, but this method is invasive and provides different results. $^{20-23}$ Therefore, this study sought to find out whether there was a relationship between NLR and the degree of steatosis and fibrosis assessed by TE and CAP.

\section{Materials and Methods}

This was a cross-sectional study. Samples were collected at Dr. Cipto Mangunkusumo National General Hospital, Jakarta based on database review from medical records in 2 years' period (2016-2018). Samples from this study using consecutive sampling techniques with inclusion criteria: (1) NAFLD patients, (2) Age over 18 years; while the exclusion criteria were (1) Hepatitis B and hepatitis C, (2) Alcohol consumption $\geq 20$ grams/day in the past 1 year, (3) Acute hepatitis, biliary obstruction, liver congestion, liver tumors, and ascites, (4) state of fever or bacterial or viral infection, (5) Patients with hematologic malignancies, (6) Patients with solid tumors, (7) Patients undergoing chemotherapy, (8) Patients with a history of cardiovascular disease, (9) Patients with autoimmune diseases, (10) Patients with aplastic anemia, myelodysplastic syndrome, (11) Patients infected with HIV, (12) Patients receiving long-term immunosuppressive therapy, (13) Incomplete research data.

Clinical evaluations, history of drugs and anthropometric were carried out at the time of Transient elastography $\left(\right.$ Fibroscan $^{\circledR}$ ) measurement. Body mass index (BMI) was calculated based on body weight in kilograms divided by the square of body height in meter. Waist circumferences were measured from the line crossing umbilicus and iliac crest. Blood pressure was measured twice with 5 minutes' rest in between examination. Blood samples were taken after a minimum of 12 hours fasting to evaluate HDL, triglyceride, leucocyte count, and fasting blood glucose. Metabolic syndrome was diagnosed according to ATP III criteria. ${ }^{10}$ TE with CAP were done to evaluate the degree of steatosis and fibrosis, with TE cutoff for significant fibrosis is $\geq 7 \mathrm{kPa}$ and CAP cutoff for moderate-severe steatosis is $\geq 259 \mathrm{~dB} / \mathrm{m}^{15,24}$ After the research was completed, the data will be processed with descriptive and analytical statistics.

\section{Statistical Analysis}

Descriptive statistics were conducted to determine the characteristics of the research subjects. Spearman or Pearson correlation will be used to assess the relationship between 
NLR and CAP and TE. To find out the intersection between NLR and degrees of steatosis or fibrosis, a receiver operating curve (ROC) will be created to obtain the Area Under the Curve (AUC). The cutoff was then processed into dichotomous categorical variables, combined and compared with the steatosis and fibrosis degree based on Fibroscan ${ }^{\circledR}$ CAP results using a $2 \times 2$ table. Based on the analysis of the $2 \times$ 2 table, sensitivity, specificity, PPV, and NPV were obtained. To avoid the metabolic syndrome as a confounding factor, a multivariate linear regression analysis was performed and to show that there was a mean difference in the value of NLR based on the degree of steatosis and fibrosis carried out $t$-test analysis. Statistical analyses were performed using Statistical Package for Social Sciences (SPSS) Version 20.0 (SPSS Inc, Chicago, Illinois). A P value $<0.05$ was considered as statistically significant. The written informed consent has been obtained from all the study subjects regarding the data and blood samples collection. This study complies with the Declaration of Helsinki, and it has been approved by The Ethics Committee of the Faculty of Medicine, University of Indonesia no: 0727/UN2.F1/ETIK/2018.

\section{Result}

\section{Characteristics of Study Subjects}

In this study, there were 106 patients diagnosed with nonalcoholic fatty liver disease (NAFLD) who can be recruited. The baseline characteristics are shown in Table 1. The mean age of the subjects was 57.29 years old with the proportion of female subjects $(62.3 \%)$ higher than men (37.7\%). Most of our study subjects are obese with central obesity dominated and had type 2 diabetes, of which 82 were included in the metabolic syndrome category.

\section{CAP and TE Correlation with Neutrophil Lymphocyte Ratio}

A strong correlation is found between CAP and NLR ( $\mathrm{r}=$ 0.648; $\mathrm{p}=<0.001$ ) using Pearson correlation test. We also found a strong correlation between TE and NLR ( $r=0.621$; $\mathrm{p}=<0.001)$ using Spearman correlation test. Pearson correlation test between CAP and NLR, and the Spearman correlation test between TE and NLR is shown in Tables 2 and 3.

\section{Effects of Metabolic Syndrome on Correlation of NLR with CAP and TE}

Multivariate linear regression analysis was performed to determine whether metabolic syndrome is a confounding
Table I Basic Characteristics of Research Subjects

\begin{tabular}{|c|c|}
\hline Variable & Total $(\mathbf{N}=106)$ \\
\hline \multicolumn{2}{|l|}{ Gender } \\
\hline Male (\%) & $40(37.7)$ \\
\hline Female (\%) & $66(62.3)$ \\
\hline Age, mean in years (SD) & $57.29(11.1)$ \\
\hline$<50$ years & $24(22.6)$ \\
\hline$\geq 50$ years & $82(77.4)$ \\
\hline BMI, mean in $\mathrm{kg} / \mathrm{m}^{2}(\mathrm{SD})$ & $28.7(4.38)$ \\
\hline $\mathrm{BMI} \geq 25(\%)$ & $89(84)$ \\
\hline $\mathrm{BMI}<25(\%)$ & $17(16)$ \\
\hline \multicolumn{2}{|l|}{ Central obesity } \\
\hline Yes (\%) & $88(83)$ \\
\hline No (\%) & $18(17)$ \\
\hline \multicolumn{2}{|l|}{ High level of blood pressure } \\
\hline Yes (\%) & $73(68.9)$ \\
\hline No (\%) & $33(31.1)$ \\
\hline \multicolumn{2}{|l|}{ Diabetes Mellitus } \\
\hline Yes (\%) & $81(76.4)$ \\
\hline No (\%) & $25(23.6)$ \\
\hline Fasting blood glucose, median in mg/dl (min-max) & II $9(4 \mid-348)$ \\
\hline Triglyceride, median in $\mathrm{mg} / \mathrm{dl}$ (min-max) & $143(19-448)$ \\
\hline High (\%) & $54(50.9)$ \\
\hline Normal (\%) & $52(49.1)$ \\
\hline HDL, median in mg/dl (min-max) & $43.5(19-116)$ \\
\hline Low (\%) & $59(55.7)$ \\
\hline Normal (\%) & $47(44.3)$ \\
\hline \multicolumn{2}{|l|}{ Metabolic syndrome } \\
\hline Yes (\%) & $82(77.4)$ \\
\hline No (\%) & $24(22.6)$ \\
\hline $\begin{array}{l}\text { Aspartate aminotransferase (AST), median in } u / l \\
(\text { min-max) }\end{array}$ & $20(12-144)$ \\
\hline $\begin{array}{l}\text { Alanine aminotransferase (ALT), median in } u / l \\
(\min -\max )\end{array}$ & $21(6-204)$ \\
\hline $\mathrm{CAP}$, mean in $\mathrm{dB} / \mathrm{m}(\mathrm{SB})$ & $283.37(42.2)$ \\
\hline Mild steatosis (\%) & $36(34)$ \\
\hline Moderate-severe steatosis (\%) & $70(66)$ \\
\hline Fibroscan $^{\circledR}$, median kPa (min-max) & $6.14(2.8-18.2)$ \\
\hline Non-significant fibrosis (\%) & $26(24.5)$ \\
\hline Significant fibrosis (\%) & $80(75.5)$ \\
\hline \multicolumn{2}{|l|}{ Drugs (\%) } \\
\hline Statin & $86(8 I .1)$ \\
\hline Anti-hypertension & $71(67)$ \\
\hline $\begin{array}{l}\text { Anti-diabetic drugs (GLP-I agonist or SGLT2- } \\
\text { inhibitor) }\end{array}$ & $0(0)$ \\
\hline Leukocytes, mean in cell/ $/ \mathrm{mm}^{3}$ (SD) & $7812.9(1782.4)$ \\
\hline Absolute neutrophil count, mean in cell $/ \mathrm{mm}^{3}$ (SD) & $4559.6(1229.9)$ \\
\hline Absolute lymphocyte count, mean in cell $/ \mathrm{mm}^{3}$ (SD) & $2433.7(67 I .2)$ \\
\hline NLR, mean (SD) & $1.96(0.58)$ \\
\hline
\end{tabular}

factor both in correlation between NLR with CAP and NLR with TE. The results of this linear regression are presented in Tables 4 and 5. Metabolic syndrome and 
Table 2 Pearson Correlation Test Between CAP and NLR

\begin{tabular}{|l|c|c|c|}
\hline Variable & Mean (SD) & $\mathbf{r}$ & $\mathbf{p}$ \\
\hline CAP & $\begin{array}{c}283.4(42.2) \\
\text { NLR }\end{array}$ & 0.648 & $<0.001$ \\
\hline
\end{tabular}

Abbreviations: CAP, controlled attenuation parameter; NLR, neutrophil to lymphocyte count ratio.

Table 3 Spearman Correlation Test Between TE and NLR

\begin{tabular}{|l|c|c|c|}
\hline Variable & Mean (SD)/Median (Min-Max) & $\mathbf{r}$ & $\mathbf{p}$ \\
\hline TE & $\begin{array}{c}6.14(2.8-18.2) \\
\text { NLR }\end{array}$ & 0.621 & $<0.001$ \\
\hline
\end{tabular}

Abbreviations: CAP, controlled attenuation parameter; NLR, neutrophil to lymphocyte count ratio.

diabetes mellitus were found not to be a confounding factor in this study, as it can be seen from the differences in the values of NLR coefficients in steps 1 and 2 less than $10 \%$ in Tables 4 and 5 . These linear regression results were also considered feasible because this correlation has a value of $p<0.001$ during Anova test.

\section{Cutoff Value of NLR in Steatosis and Fibrosis}

The optimal cutoff value of NLR to predict the degree of steatosis and fibrosis was determined using ROC curve with AUC 0.877 (95\% CI 0.814-0.941, p < 0.001) for steatosis and AUC 0.921 (95\% CI 0.842-0.999, p < 0.001) for fibrosis as shown in Figures 1 and 2. The optimal cutoff value was decided by taking the best value of both sensitivity and specificity. The optimal NLR cut off value for steatosis was 1.775 with sensitivity, specificity, PPV, and NPV, respectively, at $81.5 \%, 80.6 \%, 89.1 \%$, and $69.1 \%$, while the optimal NLR cutoff value for fibrosis was 2.150 with sensitivity, specificity, PPV, and NPV, respectively, at $92.3 \%, 87.5 \%, 70.6 \%$, and $97.2 \%$.

The cutoff value of NLR 2.320 to predict more advance stage of fibrosis (LSM $>8.1 \mathrm{kPa}$ was determined using ROC curve with AUC 0.895 (95\% CI 0.830-0.960, $\mathrm{p}=0.001)$ ). The optimal NLR cut off value with sensitivity, specificity, PPV, and NPV, respectively, at 90.9\%, $83.2 \%, 38.5 \%$, and $98.8 \%$.

The cutoff value of NLR 2.385 to predict liver cirrhosis $(\mathrm{LSM}>12.1 \mathrm{kPa})$ was determined using ROC curve with AUC 0.914 (95\% CI 0.845-0.983, p = 0.001). The optimal NLR cut off value with sensitivity, specificity, PPV, and NPV, respectively, at $100 \%, 82 \%, 25 \%$, and $100 \%$.

\section{Mean Difference of NLR Based on the Degree of Steatosis and Fibrosis}

To find out whether there are significant differences in the value of NLR on the degree of steatosis and the degree of

Table 4 Multivariate Analysis of NLR and CAP Linear Regression

\begin{tabular}{|l|l|c|c|c|}
\hline & \multicolumn{1}{|c|}{ Variables } & Coefficient & $\begin{array}{c}\text { Correlation } \\
\text { Coefficient }\end{array}$ & P value \\
\hline Step I & NLR & 45.719 & 0.626 & $<0.00$ I \\
& Metabolic syndrome & 7.842 & 0.078 & 0.302 \\
& Diabetes mellitus & 5.235 & 0.053 & 0.504 \\
& Constant & 183.78 & & $<0.001$ \\
Step 2 & NLR & 47.329 & 0.648 & $<0.001$ \\
& Constant & 190.693 & & $<0.001$ \\
\hline
\end{tabular}

Abbreviation: NLR, neutrophil to lymphocyte count Ratio.

Table 5 Multivariate Analysis of NLR and TE Linear Regression

\begin{tabular}{|l|l|c|c|c|}
\hline \multicolumn{1}{|c|}{ Variables } & Coefficient & $\begin{array}{c}\text { Correlation } \\
\text { Coefficient }\end{array}$ & P value \\
\hline Step I & NLR & 2.586 & 0.399 & $<0.001$ \\
& Metabolic syndrome & 0.366 & 0.057 & 0.488 \\
& Diabetes mellitus & 0.122 & 0.019 & 0.823 \\
& Constant & 0.696 & 0.565 & 0.421 \\
Step 2 & NLR & 2.634 & & $<0.001$ \\
& Constant & 0.979 & & 0.207 \\
\hline
\end{tabular}

Abbreviation: NLR, neutrophil to lymphocyte count ratio. 


\section{ROC Curve}

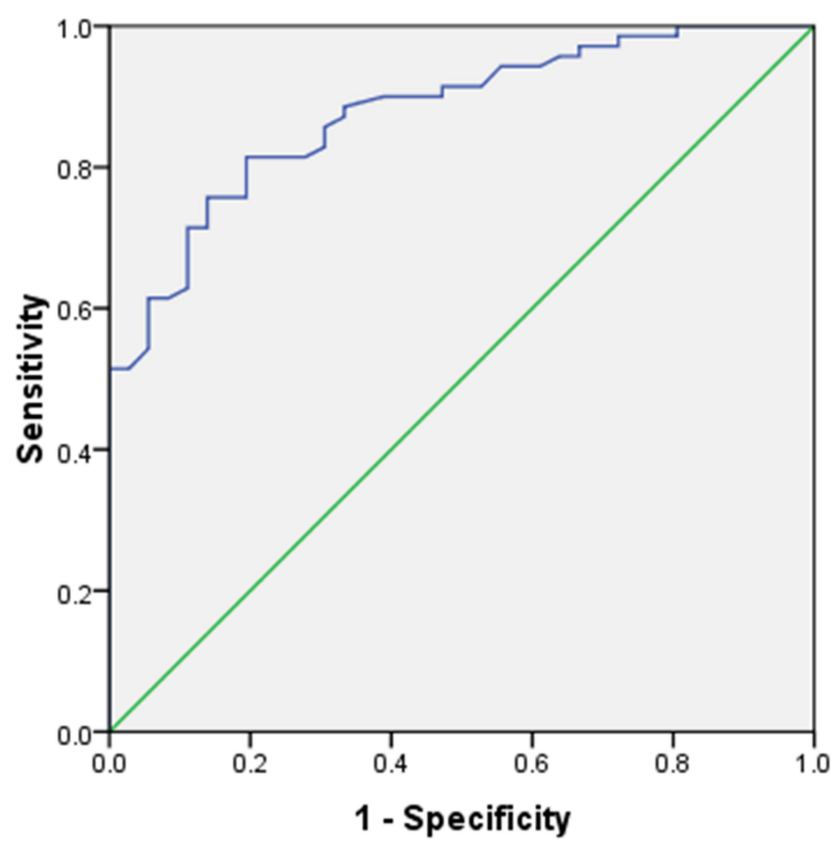

Diagonal segments are produced by ties.

Figure I NLR ROC curve for hepatic steatosis prediction.

\section{ROC Curve}

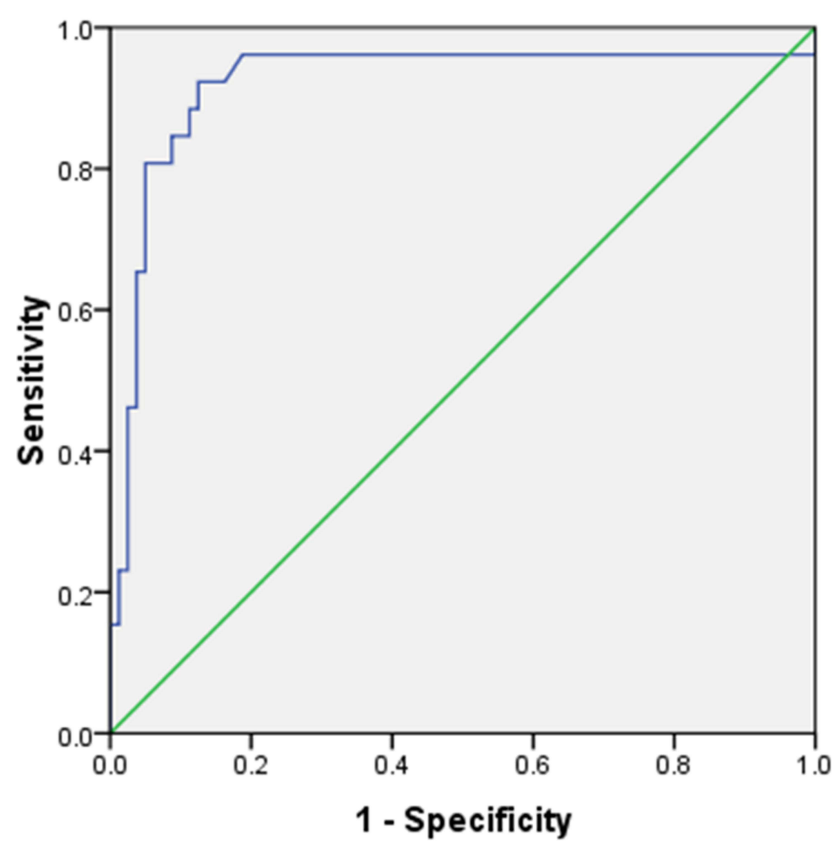

Diagonal segments are produced by ties. fibrosis, a $t$-test is performed for each group, which showed significant differences in the value of NLR to the degree of steatosis and fibrosis as shown in Tables 6 and 7.

\section{Discussion}

To the best of our knowledge, this is the first study to use TE and CAP to determine the correlation between NLR and the degree of steatosis and fibrosis of NAFLD, as studies have shown about association between NLR and NAFLD, ${ }^{13,16,20,21}$ TE and CAP as additional tool to transabdominal US for NAFLD evaluation has been validated for steatosis and fibrosis assessment. ${ }^{25}$

In this study, the proportion of women was higher than men $(62.3 \%$ vs $37.7 \%)$. This gender distribution might be differed from other study which showed that higher prevalence of NAFLD found in men. ${ }^{26}$ A study conducted by Summart et al in 2017 in Northern Thailand also resulted in a far greater number of NAFLD patients in women than men. ${ }^{27}$ However, there are several studies that link age, where $77.4 \%$ of the study subjects were over 50 years old. This is consistent with previous studies, which showed that the incidence of NAFLD in women rise dramatically after the age of 50 years and reached its peak at the age of 60 to 69 years. ${ }^{28}$ This might give an explanation the reason for higher proportion of women than men in this study. It is hypothesized that this condition was related to menopause, where study by Ryu et al showed a higher prevalence of NAFLD in menopausal patients. ${ }^{29}$

Most of the study subjects have high level of fasting blood glucose, high level of blood pressure, central obesity and metabolic syndrome, but have normal HDL level, possibly due to around $81 \%$ of the subjects are on statin medication. These results supported several theories that said NAFLD was closely related to insulin resistance, which can be found in people with type 2 diabetes mellitus. Previous studies also said that the presence of peripheral adipose due to insulin resistance was also associated with NAFLD and subsequent disease progression, both NASH and liver cirrhosis due to excessive oxidative stress. $^{6,7,30,31}$

Data analysis showed a significant positive correlation between the CAP value and NLR $(r=0.648 ; \mathrm{P}<0.001)$, with the optimal cutoff point of NLR based on the degree of steatosis was 1.775 (AUROC $=0.877,95 \%$ CI 0.814 0.941 ) with sensitivity, specificity, PPV, and NPV of $81.5 \%, 80.6 \%, 89.1 \%$, and $69.1 \%$, respectively. It showed that NLR is good enough to predict the condition of liver steatosis based on the results of the CAP examination. In

Figure 2 NLR ROC curve for hepatic fibrosis prediction. 
Table 6 Comparison of 2 Mean Analysis of NLR Values for the Degree of Steatosis

\begin{tabular}{|l|c|c|c|c|}
\hline Steatosis Degree & N & Mean NLR & Standard Deviation & p value \\
\hline Mild & 36 & 1.492 & 0.305 & $\mathrm{P}<0.001$ \\
Moderate-severe & 70 & 2.198 & 0.538 & $\mathrm{P}<0.001$ \\
\hline
\end{tabular}

Abbreviation: NLR, neutrophil to lymphocyte count Ratio.

Table 7 Comparison of 2 Mean Analysis of NLR Values for the Degree of Fibrosis

\begin{tabular}{|l|c|c|c|c|}
\hline Fibrosis Degree & N & Mean NLR & Standard Deviation & P value \\
\hline Non-significant & 80 & 1.744 & 0.415 & $\mathrm{P}<0.001$ \\
Significant & 26 & 2.617 & 0.51 & $\mathrm{P}<0.001$ \\
\hline
\end{tabular}

addition, the value of NLR in patients with moderatesevere steatosis was significantly higher than in patients with mild steatosis $(2.198 \pm 0.538$ vs $1.492 \pm 0.305)$. Increased NLR in patients with steatosis is caused by inflammation that arises due to insulin resistance condition, systemic lipotoxicity due to lipid metabolites, and the production of proinflammatory cytokines such as TNF- $\alpha$ and IL-6, adipokine and oxidative stress. ${ }^{21}$

Patients with obesity or type 2 diabetes mellitus are at risk for increased NLR with or without hepatic steatosis. This phenomenon might be due to the presence of insulin resistance and high levels of lipids in the body that trigger the production of pro-inflammatory cytokines. ${ }^{16}$ Therefore, a further linear regression analysis was conducted to find out whether metabolic syndrome and diabetes mellitus affected the correlation between NLR and CAP. It was found that metabolic syndrome and diabetes mellitus were not a confounding factor in the relationship between NLR and CAP, which is surprising given that many studies and literature that stated a close relation between metabolic syndrome with the degree of steatosis and fibrosis in NAFLD. ${ }^{9-11,32}$ In addition, a study conducted by Kara et al showed that metabolic syndrome was a significant confounding factor in the relationship of NLR with the degree of steatosis and NAFLD fibrosis. ${ }^{22}$ This difference in results may be due to the majority of the samples in this study having metabolic syndrome (77.42\%), and almost all of the samples had at least one component of metabolic syndrome, whereas in the Kara study, only 7 of 226 research subjects had metabolic syndrome.

Until now, there have been various studies showing that NLR is related to the degree of fibrosis in NAFLD patients. Research conducted by Yilmaz et al showed that the mean value of NLR in NASH patients was significantly higher than that of controls $(3.44 \pm 1.29$ and $1.9 \pm 0.7 ; \mathrm{p}<0.001)$, NLR also correlated positively with degree of fibrosis in the study $(\mathrm{r}=0.892, \mathrm{p}<0.01) .^{20}$ Another study conducted by Razik et al also showed the same results, with a correlation value of 0.75 ( $\mathrm{p}<$ $0.001) .{ }^{16}$ Alkhouri et al also showed a correlation of 0.45 $(p<0.001)$ between NLR patients with degree of fibrosis. ${ }^{21}$ On the other hand, there are also studies that showed no significant differences between NLR in patients with and without fibrosis $(p=0.212) .{ }^{22}$ In this study, apart from finding a positive, strong and significant correlation $(\mathrm{r}=0.621 ; \mathrm{p}<0.001)$, we also found a significant difference in mean NLR between patients without fibrosis with significant fibrosis patients $(\mathrm{p}<0.001)$. However, this study revealed that the optimal cut-off point of fibrosis degree based on NLR was 2.150 with sensitivity of $92.3 \%$ and $87.5 \%$ specificity. This shows that the results are quite consistent in showing the correlation between NLR and degree of fibrosis from various studies. However, it should be noted that the comparison used in this study is different from other studies. This study used TE as a comparison in determining the degree of fibrosis, while other studies used biopsy results to determine the degree of fibrosis.

Based on the linear regression test, it was found that metabolic syndrome was not a confounding factor in the correlation between NLR and TE. This is in line with the study conducted by Kanwar et al, where there was no association between metabolic syndrome status and the incidence or degree of fibrosis in NAFLD patients. ${ }^{33}$ However, other studies conducted by Kara et al showed conflicting results. ${ }^{22}$ Differences in results of the studies showed variabilities in relationship between NLR and the degree of fibrosis in patients with metabolic syndrome. Therefore, further research is needed on this matter. 
There are limitations of this study. First, this study is a cross-sectional study using secondary data, so it could not show a causal relationship. However, this study result shown the formula which is practical in daily use. Other limitations were factors that influenced NAFLD conditions such as analysis of food intake, insulin resistance (HOMAIR), genetic polymorphism, adiponectin, and gut microbiota were not assessed. However, these factors were not meant to be analysed at present.

\section{Conclusions}

There is a significant correlation between the value of NLR and the value of CAP and TE in patients with NAFLD. NLR might be used to assess the development of steatosis and fibrosis in patients with NAFLD. A large cohort prospective study would be needed to confirm these findings.

\section{Acknowledgments}

The authors would like to thank all the staff of Hepatobiliary Division, Department of Internal Medicine, Dr. Cipto Mangunkusumo National General Hospital, Universitas Indonesia, for their significant support for this study.

\section{Disclosure}

The authors report no conflicts of interest for this work.

\section{References}

1. European Association for the Study of the Liver, European Association for the Study of Diabetes, European Association for the Study of Obesity. EASL-EASD-EASO Clinical practice guidelines for the management of non-alcoholic fatty liver disease. $J$ Hepatol. 2016;64:1388-1402. doi:10.1016/j.jhep.2015.11.004

2. Chalasani N, Younossi Z, Lavine JE, Charlton M, Cusi K, Rinella M. The diagnosis and management of nonalcoholic fatty liver disease: practice guidance from the American Association for the Study of Liver Diseases. Hepatology. 2018;67:328-357.

3. Yu J, Shen J, Sun TT, Zhang X, Wong N. Obesity, insulin resistance, NASH and hepatocellular carcinoma. Semin Cancer Biol. 2013;23:483-491. doi:10.1016/j.semcancer.2013.07.003

4. Lesmana CRA, Pakasi LS, Inggriani S, Aidawati ML, Lesmana LA. Development of non-alcoholic fatty liver disease scoring system among adult medical check-up patients: a large cross-sectional and prospective validation study. Diabetes Metab Syndr Obes Targets Ther 2015;8:213-218. doi:10.2147/DMSO.S80364

5. Loomba R, Sanyal AJ. The global NAFLD epidemic. Nat Rev Gastroenterol Hepatol. 2013;10:686-690. doi:10.1038/ nrgastro.2013.171

6. Milic S, Lulic D, Stimac D. Non-alcoholic fatty liver disease and obesity: biochemical, metabolic and clinical presentations. World J Gastroenterol. 2014;20(28):9330-9337. doi:10.3748/wjg.v20.i28.9330
7. Sapmaz F, Uzman M, Basyigit S, Ozkan S, Yavuz B, Yeniova A. Steatosis grade is the most important risk factor for development of endothelial dysfunction in NAFLD. Med. 2016;95(14):1-7.

8. Castera L, Hezode C, Roudot-Thoraval F, Bastie A, Zafrani ES, Pawlotsky JM. Worsening of steatosis is an independent factor of fibrosis progression in untreated patients with chronic hepatitis $\mathrm{C}$ and paired liver biopsies. Gut. 2003;52(2):288-292. doi:10.1136/ gut.52.2.288

9. Tao X, Liu Q, Wang Z. Metabolic syndrome is a risk factor for nonalcoholic fatty liver disease: evidence from a confirmatory factor analysis and structural equation modeling. Eur Rev Med Pharmacol Sci. 2016;20:4313-4321.

10. Paschos P, Paletas K. Non alcoholic fatty liver disease and metabolic syndrome. Hippokratia. 2009;13(1):9-19.

11. Abd El-Kader SM, El-den Ashmawy EMS. Non-alcoholic fatty liver disease: the diagnosis and management. World J Hepatol. 2015;7 (6):846-858. doi:10.4254/wjh.v7.i6.846

12. Shiha G, Ibrahim A, Helmy A, Sarin SK, Omata M, Kumar A. AsianPacific Association for the Study of the Liver (APASL) consensus guidelines on invasive and non-invasive assessment of hepatic fibrosis: a 2016 update. Hepatol Int. 2017;11(1):1-30. doi:10.1007/ s12072-016-9760-3

13. Asil M, Dertli R. The neutrophil-to-lymphocyte ratio as a noninvasive marker in patients with biopsy-proven non-alcoholic steatohepatitis. Istanbul Med J. 2016;131-135. doi:10.5152/ imj.2016.74755

14. Sasso M, Beaugrand M, de Ledinghen V, Douvin C, Marcellin P, Poupon R. Controlled attenuation parameter (CAP): a novel VCTE guided ultrasonic attenuation measurement for the evaluation of hepatic steatosis: preliminary study and validation in a cohort of patients with chronic liver disease from various causes. Ultrasound Med Biol. 2010;36(11):1825-1835. doi:10.1016/j.ultrasmedbio. 2010.07.005

15. Machado MV, Cortez-Pinto H. Non-invasive diagnosis of non-alcoholic fatty liver disease. A critical appraisal. $J$ Hepatol. 2013;58(5):1007-1019. doi:10.1016/j.jhep.2012.11.021

16. Abdel-Razik A, Mousa N, Shabana W, Refaey M, ElMahdy Y, Elhelaly R. A novel model using mean platelet volume and neutrophil to lymphocyte ratio as a marker of nonalcoholic steatohepatitis in NAFLD patients. Eur J Gastroenterol Hepatol. 2016;28(1):e1-e9. doi:10.1097/MEG.0000000000000486

17. Harmon RC, Tiniakos DG, Argo CK. Inflammation in nonalcoholic steatohepatitis. Expert Rev Gastroenterol Hepatol. 2011;5 (2):189-200. doi:10.1586/egh.11.21

18. Meli R, Raso GM, Calignano A. Role of innate immune response in non-alcoholic fatty liver disease: metabolic complications and therapeutic tools. Front Immunol. 2014;5(4):1-14. doi:10.3389/ fimmu.2014.00177

19. Mohamed NR, Assem M, Atef A, et al. Neutrophil to lymphocyte ratio as a new marker for predicting steatohepatitis in patients with nonalcoholic fatty liver disease. Int $J$ Adv Res. 2015;3(10):688-697.

20. Yilmaz H, Yalcin KS, Namuslu M, Celik HT, Sozen M, Inan O. Neutrophil-lymphocyte ratio (NLR) could be better predictor than C-reactive protein (CRP) for liver fibrosis in non-alcoholic steatohepatitis (NASH). Ann Clin Lab Sci. 2015;45(3):278-286.

21. Alkhouri N, Morris-Stiff G, Campbell C, Lopez R, Tamimi TAR, Yerian L. Neutrophil to lymphocyte ratio: a new marker for predicting steatohepatitis and fibrosis in patients with nonalcoholic fatty liver disease. Liver Int. 2012;32(2):297-302. doi:10.1111/j.14783231.2011.02639.x

22. Kara M, Dogru T, Genc H, Sertoglu E, Celebi G, Gurel H. Neutrophil-to-lymphocyte ratio is not a predictor of liver histology in patients with nonalcoholic fatty liver disease. Eur J Gastroenterol Hepatol. 2015;27(10):1144-1148. doi:10.1097/MEG.0000000000 000405 
23. Malhotra P, Marwaha N, Marwaha S, Malhotra V, Malhotra N. Noninvasive biomarkers vs liver biopsy in diagnosing and staging NAFLD. Adv Res Gastroentero Hepatol. 2015;1(2):555559. doi:10.19080/ARGH.2015.01.555559

24. De Ledinghen V, Vergniol J, Capdepont M, Chermak F, Hiriart JB, Cassinotto C. Controlled attenuation parameter (CAP) for the diagnosis of steatosis: a prospective study of 5323 examinations. J Hepatol. 2014;60(5):1026-1031. doi:10.1016/j.jhep.2013.12.018

25. Wang Y, Fan Q, Wang T, Wen J, Wang H, Zhang T. Controlled attenuation parameter for assessment of hepatic steatosis grades: a diagnostic meta-analysis. Int J Clin Exp Med. 2015;8(10):17654-17663.

26. Lonardo A, Bellentani S, Argo CK, Ballestri S, Byrne CD, Caldwell SH. Epidemiological modifiers of non-alcoholic fatty liver disease: focus on high-risk groups. Dig Liver Dis. 2015;47 (12):997-1006. doi:10.1016/j.dld.2015.08.004

27. Summart U, Thinkhamrop B, Chamadol N, Khuntikeo N, Songthamwat M, Kim C. Gender differences in the prevalence of nonalcoholic fatty liver disease in the Northeast of Thailand: a population-based cross-sectional study. F1000research. 2017;6:1-17. doi:10.12688/f1000research.12417.1

28. Bertot LC, Adams LA. The natural course of non-alcoholic fatty liver disease. Int J Mol Sci. 2016;17(5):774.
29. Ryu S, Suh B, Chang Y, Kwon M, Eun K, Jung H. European journal of obstetrics and gynecology and reproductive biology menopausal stages and non-alcoholic fatty liver disease in middle-aged women. Eur J Obstet Gynecol. 2015;190:65-70. doi:10.1016/j.ejogrb.2015. 04.017

30. Younossi ZM, Koenig AB, Abdelatif D, Fazel Y, Henry L, Wymer M. Global epidemiology of nonalcoholic fatty liver disease in meta-analytic assessment of prevalence, incidence, and outcomes. Hepatology. 2016;64(1):73-84. doi:10.1002/hep.28431

31. Wei Y, Tian Q, Zhao X, Wang X. Serum transforming growth factor beta 3 predicts future development of nonalcoholic fatty liver disease. Int J Clin Exp Med. 2015;8(3):4545-4550.

32. Mikolasevic I, Orlic L, Franjic N, Hauser G, Stimac D, Milic S. Transient elastography $\left(\right.$ FibroScan $\left.{ }^{\circledR}\right)$ with controlled attenuation parameter in the assessment of liver steatosis and fibrosis in patients with nonalcoholic fatty liver disease - Where do we stand? World J Gastroenterol. 2016;22 (32):7236-7251. doi:10.3748/wjg.v22.i32.7236

33. Kanwar P, Nelson JE, Yates K, Kleiner DE, Unalp-Arida A, Kowdley KV. Association between metabolic syndrome and liver histology among NAFLD patients without diabetes. BMJ Open Gastroenterol. 2016;3(1):e00114. doi:10.1136/bmjgast-2016-000114

\section{Publish your work in this journal}

Diabetes, Metabolic Syndrome and Obesity: Targets and Therapy is an international, peer-reviewed open-access journal committed to the rapid publication of the latest laboratory and clinical findings in the fields of diabetes, metabolic syndrome and obesity research. Original research, review, case reports, hypothesis formation, expert opinion and commentaries are all considered for publication. The manuscript management system is completely online and includes a very quick and fair peer-review system, which is all easy to use. Visit http://www.dovepress.com/testimonials.php to read real quotes from published authors. 